\title{
OS PROCESSOS DE NEGAÇÃO DA MEMÓRIA E DA IDENTIDADE NEGRA EM "A MÁSCARA" DE GRADA KILOMBA
}

\author{
THE PROCESSES OF DENIAL OF BLACK MEMORY AND IDENTITY IN "THE MASK" \\ BY GRADA KILOMBA
}

\section{Géssica Brito Santos ${ }^{1}$}

RESUMO: O presente artigo tem como objetivo analisar no texto "A máscara", da escritora portuguesa Grada Kilomba, os processos de memória coletiva e traumas herdados da imagem que foi direcionada ao negro escravizado, a partir das marcas do colonialismo. No critério de definição dessas marcas é que se chega aos sujeitos sociais e tudo que constitui sua relação com o presente e o passado. Por isso, cotejando a essa análise, investiga-se a elucidação do conceito de memória e identidade enquanto objeto de estudo biológico e social, como defende Joël Candau (2008). Em função disso, faz-se a investigação de como a memória e a identidade estão apoiadas em uma perspectiva de definição dos atores sociais, de suas ações e de suas capacidades de encarnarem uma identidade pessoal e coletiva, quando se imagina os conflitos que envolvem um estudo psicanalítico do sujeito e da reconstituição do passado histórico.

Palavras-chave: Memória. Identidade. Trauma. Colonização. Repressão.

ABSTRACT: This article aims to analyze in the text "The mask", by the Portuguese writer Grada Kilomba, the processes of collective memory and traumas inherited from the image that was directed to the enslaved black, from the marks of colonialism. It is based on the criterion of definition of these marks that one reaches the social subjects and everything that constitutes their relationship with the present and the past. Therefore, in comparison to this analysis, the elucidation of the concept of memory and identity as an object of biological and social study, as argued by Joël Candau (2008), is investigated. With that in mind, the investigation comprises of how memory and identity are supported by a perspective of definition of social actors, their actions and their abilities to embody a personal and collective identity, when one imagines the conflicts that involve a psychoanalytic study of the subject and the reconstitution of the historical past.

Keywords: Memory. Identity. Trauma. Colonization. Repression.

\section{Considerações iniciais}

O colonialismo modificou as maneiras de pensar de vários povos e culturas, alterou o sentido de uma crítica da alteridade humana, modificou também o modo como se desenvolveu as relações de poder e as composições de epistemologias não hegemônicas. Não obstante, quando se fala daquele que foi escravizado e da manipulação de seu conhecimento, de sua cultura e de sua humanidade, é

\footnotetext{
I Graduada em Letras pela Universidade do Estado da Bahia - UNEB. Mestranda em Letras: linguagens e representações pela Universidade Estadual de Santa Cruz- UESC, Ilhéus - Bahia. E-mail: gessicabbrito@hotmail.com.
} 
importante que se observe uma soma de fatores que contribuíram para patentear um pensamento ocidental pautado na universalidade branca, europeia e dominante.

Para Fanon (196r), o racismo não é apenas um problema político e econômico, mas um problema de alienação psíquica, um problema que se projeta para o campo das causas psicológicas do sujeito e na forma como ele pensa e existe no mundo. Isso remete a uma série de abordagens no que diz respeito a identidade e a escalada de consciência do sujeito, isto é, a forma como ele exercita a reflexão de sua atuação social e de sua representação, e mais que isso, a forma como ele interage com seu passado histórico e, ideologicamente, o configura.

A não perder de vista essa discussão, é que se propõe uma investigação acerca desses fatores na construção da identidade negra. A saber, o estudo sobre como os discursos do colonialismo e da escravidão modelaram de forma política, social e psicologicamente a identidade negra, de modo que, as questões relacionadas ao negro estão imbricadas em uma dimensão complexa de entendimento não apenas do ser negro, como do papel fundador da memória individual e coletiva para o confronto com passado histórico na resolução ou elucidação de questões presentes. Nesse sentido, o trabalho versa pela análise dessas proposições no texto "A máscara: colonialismo, Memória, Trauma e Descolonização”, capítulo primeiro do livro Memórias da plantação, da escritora portuguesa Grada Kilomba ${ }^{2}$.

Entende-se que o livro de Kilomba, é um estudo que aprimora reflexões sobre a identidade e a memória por um prisma bastante desafiador, no sentido em que se trabalha a ideia de racismo e alteridade de ponto de vista ontológico do termo. Grada Kilomba apresenta um texto em que se discorre sobre como foi implantado no pensamento ocidental e universalizante, um discurso de negação do sujeito negro. Por meio disso, o presente artigo se ocupa da discussão em que a autora vai analisar os princípios mnésicos do ser consciente e inconsciente, da repressão e dos traumas do sujeito negro, categorias que, segundo ela, vão configurar até mesmo a percepção das terminologias Eu/Outro (a) como uma violência linguística, identitária e social.

Ainda nesse contexto de colonização, que pede que revisitemos o conceito de memória e identidade, iremos abarcar à questão, além de Frantz Fanon e Achille Mbembe, as ideias de memória e identidade do pensador e antropólogo francês Joël Candau (2008), sobre como ele consegue constituir a ideia de que a memória e a identidade estão na gama de um pensamento dicotômico, e

\footnotetext{
${ }^{2}$ Grada Kilomba (Lisboa, 1968) tem formação em psicologia, além de ser artista, teórica, docente e escritora. Ganhou notoriedade acadêmica com a publicação do livro Plantation Memories: Episodes of Everyday Racism, publicado em 2008 na Alemanha, onde vive desde que saiu do país de origem, Portugal, para concluir seus estudos. No Brasil, o livro de Kilomba foi traduzido e publicado apenas em 2019, onde teve boa recepção da crítica sendo apresentado na Bienal de São Paulo e se tornado o livro mais vendido da Festa Literária Internacional de Paraty - FLIP de 2019.
} 
que tal conflito vai influenciar a maneira como os atores sociais legitimam pensamentos. E a contribuição do historiador francês Jacques Le Goff (1990), que vai se firmar num discurso da compreensão entre a memória e a dialética da história, através do qual ele procura fazer um percurso histórico baseado na formação cultural dos sujeitos de sociedades históricas e primitivas, e desse percurso ele tece observações sobre os registros, vivência e os elementos que compõem e dão o efeito mítico à memória.

\section{A discussão da projeção psicológica de trauma na identidade negra}

A memória é provida de diferentes tessituras, do trabalho para com seu sentido cognitivo, com aquilo que está relacionado aos mecanismos biológicos do consciente e inconsciente, e com as indagações do sujeito e sua construção (CANDAU, 2018, p. 6o), o que acaba por determinar um estudo acerca da identidade, isto é, acerca da visão ideológica pessoal ou coletiva que cada um pode desenvolver.

Para Candau (2018, p. 6I), a relação transversal da memória e da identidade abriga processos que, à rigor, não cabem em um sentido limitado de organização dos acontecimentos passados. Isso é o mesmo que dizer que dentro desse sistema mnésico humano existem falhas, perdas, transtornos e emoções que interferem na imagem que formamos de nós mesmos, seja na individualidade, seja nos grupos para os quais relacionamos nossa identidade.

Atrelada à memória se encontram as lembranças, e com elas, surgem imbricações para o conhecimento da memória enquanto fenômeno, que envolve um entendimento de caráter biológico, social e psicológico. O que resulta desse diálogo, é a constante afirmativa da memória e da identidade como fatores indissociáveis, por abrigar uma discussão no âmbito da apreensão externa e social dos sujeitos.

É por meio desse propósito, de refletir em um contexto de memória coletiva, qual a relação do sujeito histórico com as marcas deixadas pelo sistema colonial. Entrelaça-se a essa questão, o texto “A máscara: colonialismo, Memória, Trauma e Descolonização”, presente no livro Memórias da plantação (2019), da escritora e teórica portuguesa, Grada Kilomba. A autora tece uma análise acerca das camadas do trauma identitário e do racismo direcionado ao negro e sua imagem.

Kilomba (2019) utiliza como teorização a noção freudiana de repressão, na tentativa de argumentar seu ponto de vista sobre como esse fator incide em um contexto de memória pessoal e coletiva do sujeito ao ter que relacionar sua identidade a um evento histórico. Ela tentar explicar que o racismo se construiu a partir de um sistema bárbaro de inferiorização do negro e sua cultura, e ainda, que esse sistema é o responsável por modificar a noção de representação social e ideológica do negro em todo entendimento antropológico humano. Boaventura (2008) observa que "A ignorância 
colonialista consiste na recusa do reconhecimento do outro como igual e na sua conversão em objecto e assumiu historicamente três formas distintas: o selvagem, a natureza e o Oriente." (BOAVENTURA, 2008, p. 22). O debate é, como o branco colonizador conseguiu institucionalizar um discurso de que o negro é inferior ao branco, do ponto de vista biológico e antropológico.

Grada Kilomba em seu texto contra argumenta essa base de pensamento apresentando a noção da imagem do Outro (a) imposta ao negro (a) escravizado. Baseando-se na ideia da memória colonial como tomada por esse diálogo constante com a psicanálise do eu, do trauma e da perda identitária quando se pensa no sujeito histórico (KILOMBA, 2019, p. 34), ela incorpora à sua abordagem os elementos do discurso de desmantelamento da identidade atribuída ao negro, propondo a análise da imagem do Eu/Outro traumático que se operou a partir da negação do racismo.

O processo de colonização constituiu-se de um extermínio da cultura e humanidade da pessoa negra. A natureza brutal de tal ato é contada pela história, pelos registros e documentos, mas à memória cabe o processo de reconstituição desses traumas, por cada um em sua pessoalidade ou em estímulo a uma reflexão conjunta. É possível definir que a colonização foi um sistema de brutalidade, não apenas físico e político, assim como também identitário. É isso que Kilomba elucida em seu texto quando alega que pelo resgate da memória fica evidente os rastros da negação da origem de uma identidade negra. De toda forma, Kilomba vem propor uma denúncia de quanto essa negação, significou uma porta para ratificar um discurso de exclusão.

Mbembe (2014, p. 159) observou três dimensões da escravidão. A de anulação do sujeito social, a da brutalidade e a que "atacava o sistema nervoso e procurava extinguir todas as capacidades de as suas vítimas criarem um mundo de símbolos próprios".

Excluir os registros ou impedir que se tenha conhecimento de algo é o mesmo que negar sua existência, ao passo que restituir seria reconhecer sua identidade como lembra Candau (2018, p. 68). A memória se mostra sempre receptiva ao princípio de "intenções de valores". Desta forma, selecionar (esquecer/lembrar) seria uma atividade que se encontra integrada à ação cognitiva e à imaginação humana. Seleciona-se aquilo que de alguma maneira será utilizado no processo de definição social do sujeito. Quando há fratura em seu passado, nos casos de amnésia, esquecimento e transtornos da memória, o sujeito é tomado pela perda de si. Um sujeito sem passado, para Candau, é um sujeito sem identidade (CANDAU, 2018, p. 6r).

A memória em termos de matéria biológica, é vista como um sistema organizador sensível à estímulos mnésicos. É por meio desse sistema que se encontra o constante conflito de consciência que o sujeito desenvolve sobre si mesmo, sobre sua visão de mundo, e sobre a relação com outros sujeitos e grupos sociais. É possível afirmar que "a memória e a recordação põem efectivamente em 
jogo toda uma estrutura de órgãos, todo um sistema nervoso, toda uma economia de emoções no centro das quais está necessariamente o corpo e tudo o que o ultrapassa." (MBEMBE, 2014, p. 2008).

Isso permite-se chegar a um ponto determinante, os conflitos de memória, esquecimentos, traumas, amnésias e sensação de perda, devem ser traduzidos como um transtorno patológico que tem seus efeitos estendidos à constituição mnésica dos sujeitos históricos.

Diante desse argumento de que a amnésia, em seu sentido traumático, passaria também a ser um fenômeno social, isto é, envolveria o sujeito e a consciência de si, suas lembranças e como ele reconstitui o passado, encontra-se a formulação trazida por Kilomba. Segundo ela, a escravidão teve um sistema tão brutal, que até mesmo ao sujeito branco era forçoso a aceitação de sua imagem de “vilão", levando-o a optar por transferi-la ao negro. Ou seja, a discussão aqui envolve esse processo de amnésia do branco, quando ele apreende do sujeito negro sua identidade, e a tentativa de recuperação dessa identidade no acesso amnésico ao seu passado histórico, por meio de reflexões e buscas. Essas reflexões provocam no sujeito negro um sentimento de pertencimento, e o faz passar a questionar essa perda de si a partir das marcas adulteradas do seu passado, como aponta Mbembe (2014) ao constituir essa violência como fenomênica, aquela que envolve fatores psíquicos em caráter de identidade do sujeito. Segundo o autor, "uma das suas funções era esvaziar o passado do colonizado de qualquer substância e, pior ainda, privá-lo de futuro.” (MBEMBE, 2014, p. 276).

Quando existe esse tipo de perda ou esquecimento, como o que é comentado por Kilomba sobre o sujeito branco, seria algo próximo do que Candau pontua como irrupções mnésicas. Para ele, se trata de uma experiência em se constata "impressões insuportáveis, quer dizer, lembranças que não se ousa confessar aos outros e, sobretudo, a si próprio, pois elas colocariam em risco a imagem que se faz de si mesmo." (CANDAU, 2018, p. 64).

O texto de Kilomba, explora essas dimensões da investigação da memória. Observa-se a argumentação relativa à manipulação do passado que se operou a partir do silenciamento do sujeito negro. O símbolo maior dessa brutalidade está na máscara utilizada pela escrava negra Anastácia acessório que cobria todo o rosto ou boca do negro para que ele fosse impedido de falar. A máscara, como descreve Kilomba, é mais do que um simples acessório, é o símbolo de trauma e violência imposta ao negro, uma tentativa de estigmatizar sua identidade pela dominação desumana de seu corpo. É o símbolo de animalização do ser humano, afinal, aquele que está impedido de falar não oferece riscos de protestar um estado presente ou passado.

Mbembe (2014) aponta para essa direção quando distingue a política do silenciamento pelas três dimensões de escravidão. Para ele:

${ }_{3}^{3}$ Cf. Em nota, Kilomba comenta quem foi a escrava Anastácia e como sua imagem se tornou um símbolo da brutalidade da escravidão (KILOMBA, 2019, p. 35). 
A violência colonial era, por fim, uma violência fenoménica. Nessa medida, tocava tanto os domínios dos sentidos como os domínios psíquicos e afectivos. Provocava problemas mentais difíceis de curar e de tratar. Excluía qualquer dialéctica de reconhecimento e era indiferente a qualquer argumento moral. No que respeita ao tempo, um dos quadros mentais privilegiados de qualquer subjectividade, fazia os colonizados arriscarem-se a perder o uso de quaisquer rastos mnésicos [...]. (MBEMBE, 2014, p. 276).

Assim, no exercício cotidiano de brutalidade, ameaça e alteração de valores construiu-se um discurso em que o negro é posto como aquele que quer usurpar algo do branco, como o vilão que causa o sofrimento. "O sujeito negro torna-se então tela de projeção daquilo que o sujeito branco teme reconhecer sobre si mesmo, neste caso: a ladra ou o ladrão violenta/o, a/o bandida/o indolente e maliciosa/o.” (KILOMBA, 2019, p. 37, grifos da autora).

Assim, recobrando ao texto de Kilomba, esse processo de desmoralizar a identidade negra é considerado pela autora como Outro (antagonista do $\mathrm{Eu}$ ), que corresponde a tentativa do sujeito branco em transferir para o sujeito negro (outro) as características negativas que ele rejeita em si. Para ela:

Em termos psicanalíticos, isso permite que os sentimentos positivos em relação a si mesma/o permaneçam intactos - branquitude como a parte "boa" do ego enquanto as manifestações da parte "má" são projetadas para o exterior e vistas como objetos externos e "ruins". (KILOMBA, 2019, p. 37).

Assim, problematiza-se a ideia do Outro. A identidade negra, a personalidade e história do sujeito negro é definida pelo olhar do sujeito branco que o enxerga no papel de submisso. Para Frantz Fanon (2008), a dimensão dialética do Eu e do Outro é que sustenta o pensamento de alteridade dos atores sociais, o racismo faz com que se opere uma ruptura nesse sistema, de modo que o sujeito negro seja desligado dessa base e esteja propenso a todo tipo de violência. Desse modo, para ele a briga se concentra na retomada dessa dimensão social, e principalmente, na possibilidade de o negro ditar sua própria identidade.

Nesse sentido, retomo ao pensamento de Candau ao elucidar que, em contornos psicanalíticos, a memória é afetada por essa transformação "essencial” do passado (CANDAU, 2018, p. 63), que vai influenciar a maneira como o sujeito toma consciência de sua identidade, e estando em ausência, na perda de identidade.

Le Goff (1990) aponta um sentido metafórico para a amnésia se refletida por um viés de um fenômeno social. A amnésia não apenas se caracteriza como uma "falta ou uma perda" consciente ou inconsciente da memória, como também atravessa a pessoalidade de cada sujeito e sua relação com a memória coletiva, aquela que é "essencialmente mítica, deformada, anacrônica, mas constitui o vivido desta relação nunca acabada entre o presente e o passado" (LE GOFF, 1990, p. 29), isto é, 
aquela que é direcionada a uma reflexão conjunta dos eventos do passado, e como tais eventos podem ser exercitados continuamente no pensamento ideológico de grupos sociais, a partir da sensação de pertencimento dos sujeitos. Ou seja, a memória tem o poder de promover sujeitos atuantes e de fazer com que os atores socais reclamem por seu lugar.

Le Goff acredita que:

A memória, como propriedade de conservar certas informações, remete-nos em primeiro lugar a um conjunto de funções psíquicas, graças às quais o homem pode atualizar impressões ou informações passadas, ou que ele representa como passadas. (LE GOFF, 1990, p. 423).

Desse modo, a função da memória é a de acessar o passado a partir do presente para uma formação ideológica individual ou coletiva. A questão é que esses acessos, diferente do que acontece com a história, não passa pelo julgo crítico do um investigador/historiador.

Essa discussão é muito pontual quando Le Goff dá um sentido de confluência para os fundamentos da memória e da história, no sentido de que, segundo ele, a memória atua como um nível de organização da história. O autor aponta que enquanto "a memória faz parte do jogo do poder, se autoriza manipulações conscientes ou inconscientes, se obedece aos interesses individuais ou coletivos, a história, como todas as ciências, tem como norma a verdade”. (LE GOFF, 1990, p. 32). Pensando por esse viés, a memória é definida como aquela que acaba incorporando características ligadas à emoção, influência e estímulos externos que vão diversificar o olhar individual e coletivo do passado.

Nesses termos, a memória pode ser compreendida como uma representação do passado, ou se configura como a continuidade do passado a partir das experiências presentes e com o exercício de percepção das coisas úteis, como defende Bergson (1999, p. 69). Dessa maneira, ela seria como um estatuto de representação do passado, não sendo pensada sem as relações interpessoais e sem a inteligibilidade sobre o mundo a partir das experiências do sujeito.

É, precisamente, desse ponto que vemos a relação entre a memória traumática da colonização, e aquilo que foi imputado ao negro em termos de identidade cultural. Para Frantz Fanon a principal consequência do colonialismo para o sujeito negro foi a atribuição desumana destinada a ele:

Como é uma negação sistemática do outro, uma decisão furiosa de privar o outro de qualquer atributo de humanidade, o colonialismo leva o povo dominado a perguntar-se constantemente: "Quem sou eu na realidade?”. (FANON, ig6r, p. 263).

A política do sujeito branco de impor pelo silêncio, que, progressivamente, vai contornar o pensamento coletivo, foi um processo mnésico de perda inconsciente, vinda da capacidade do 
colonizador em classificar as lembranças do ato, a imagem de si como o responsável pelo ato, e a afirmação do negro como raça inferior. Esse pensamento é suscitado por Mbembe:

A violência colonial era uma violência empírica. Encerrava a vida quotidiana do povo colonizado num modo simultaneamente reticular e molecular [...]. Tal violência molecular havia-se infiltrado até na linguagem. Esmagava com o seu peso todas as facetas da vida, inclusivamente a da fala. Manifestava-se sobretudo nos comportamentos quotidianos do colonizador a respeito do colonizado: agressividade, racismo, desprezo, intermináveis rituais de humilhação, condutas homicidas [...]. (MBEMBE, 2014, p. 276).

Tudo isso, foi imposto no passado, de tal modo que, a aceitação da escravidão e da ideia do sujeito negro como inferior, foi elevada quase ao senso comum no pensamento ocidental, ao passo que, considerou-se natural e mais apropriado ainda sua exploração e vilipendio de sua cultura e identidade. Esse foi o pensamento enraizado na história.

Assim como Kilomba em seu texto, Candau também comenta a abordagem da repressão, ao falar de transtornos mnésicos e a faculdade do Eu na condução dos estudos psicanalíticos freudianos sobre a memória. De certa maneira, ele observa os caminhos da organização mnésicas, apontando as imbricações do que ele trata como cura analítica.

A noção de repressão da energia pulsante do inconsciente, compatível com certas teorias biológicas, é, portanto, fundamental para compreender os mecanismos que permitem ao sujeito impedir a devastação pelo passado da imagem que ele faz de sua identidade no presente. Desse ponto de vista se afirma o caráter ambivalente da memória no jogo identitário, pois ela pode simultaneamente organizar ou desorganizar a construção da uma imagem satisfatória de si própria. (CANDAU, 2018, p. 64).

Para Candau (2018, p. 64), se a amnésia tenciona perda ou falta, os processos que desencadeiam essas tensões no sujeito (esquecimentos, falha, influências exteriores), podem oferecer uma série de experiências traumáticas, que se localizam entre a identidade do sujeito e a exclusão de fatos do passado. Em outras palavras, as impressões que julgamos insuportáveis, as dolorosas, as que são dignas de condenação e que se "toca na ferida", ou que leva o sujeito a esconder a verdade de si para si mesmo, é em termos psicanalíticos a tensão de processos amnésicos do sujeito histórico.

O "virar a página" para "voltar a ser ele mesmo" (CANDAU, 2018, p. 65), talvez demonstre ser a maior reconstituição da identidade de si após a perda. É amparado nesse diálogo, que Kilomba (2019) apresenta a política do empenho por parte do branco em manter o discurso de inferioridade do negro. Isso se constitui como a recusa dos seus atos. Para ela, o sujeito branco pôde desviar-se da verdade utilizando sempre artifícios que a ignorava.

Esse é o processo pelo qual ideias - e verdades - desagradáveis se tornam inconscientes, vão para fora da consciência devido à extrema ansiedade, culpa ou vergonha que causam. Contudo, enquanto enterradas no inconsciente como 
segredos, permanecem latentes e capazes de ser reveladas a qualquer momento. (KILOMBA, 2019, p. 4I).

Foi desse modo também, que o ato de falar tornou-se simbolicamente impossível, de maneira que, todo argumento do sujeito negro, dentro dessa perspectiva do Outro, tornou-se inverossímil. Embora hoje, o discurso tenha sido desmantelado e concebe-se à palavra como, reivindicar uma identidade, esse, só foi restituído à custo de um complexo processo de resgate de memória coletiva.

Isso acabou sendo perpetuado devido ao mutismo do sujeito escravizado, que na visão de Kilomba se constitui como um trauma, porque o negro foi forçado a conviver com a imagem forjada de si e com as marcas deixadas pelo sistema colonialista na sua cultura. A palavra dominadora do homem branco levou o homem negro a, progressivamente, ser considerado o Outro. Isto é, "a/o 'outra/o' não é 'outra/o' per se; ela/ele torna-se através de um processo de absoluta negação." (KILOMBA, 2019, p. 38, grifos da autora).

Em suma, falar de memória a partir de um fato histórico significa repensar o passado modelando novas percepções individuais e coletivas à história contada.

A memória foge ao olhar crítico e constrói uma visão mais limitada e tomada de percepções voluntárias ou involuntárias, que dizem respeito a emoção, ao esquecimento e a perdas que afetam cada um individualmente ou em um grupo. Nessa seara, surge o debate da memória coletiva e, consequentemente, a ideia de pertencimento quando direcionamos nossa forma de pensar para as marcas deixadas por um acontecimento histórico na concepção de uma identidade coletiva. Do mesmo modo que, falar de colonialismo e racismo se encontra integrado à discussão da memória, porque se imagina os conflitos de consciência, a representação do passado e a identidade dos atores sociais.

\section{Considerações finais}

O artigo procurou analisar o texto da escritora Grada Kilomba, "A máscara: colonialismo, Memória, Trauma e Descolonização", no intuito de suscitar uma discussão acerca da identidade negra e dos traumas decorrentes do sistema de colonização. Nesse contexto, apresentou-se uma reflexão sobre a memória, procurando distinguir os elementos que a aproximam de uma crítica ao reconhecimento do sujeito e da sua identidade.

Observou-se que a explicação sobre a noção de amnésia e trauma não é apenas uma questão patológica, quando se tem em pauta a noção dos conceitos que determinam a ligação entre os componentes da memória e da identidade, mas, se encontra na linguagem do sujeito com o mundo, com o reconhecimento de si e a relação com os acontecimentos passados. 
Em se tratando do texto de Grada Kilomba, ficou evidente que a culpa do sujeito branco, esta, tratada como principal objeto de análise pela autora, e que determinou o modo como se operou a exploração do branco contra o negro, é uma experiência do medo de ser desvelada uma acusação. A forma de calar, de vedar a boca do sujeito negro, estaria ligada a maneira de fazer com ele não falasse as verdades das quais o branco tentava banir de sua imagem. Fica claro que, a identidade do sujeito negro foi conquistada depois de trabalho constante de regaste à memória coletiva. Ou seja, somente os registros historiográficos não dão conta de fazer esse papel de relacionar o sujeito, à imagem que ele faz de si mesmo e ao seu passado. Assim, a função da memória para se pensar na posição do sujeito histórico e de determinados grupos, passa pelo trabalho que envolve um diálogo com a própria organização voluntária ou involuntária da memória biológica, com os transtornos decorrentes dessa irrupção, e também, com esse trabalho de resgate de uma identidade pessoal e coletiva.

\section{Referências}

BERGSON, Henri. Matéria e Memória: ensaio sobre a relação do corpo com o espírito / Henri Bergson; tradução Paulo Neves. - 2- ed. - São Paulo: Martins Fontes, 1999. - 291 p. (Coleção tópicos).

BOAVENTURA, S. S. Do pós moderno ao pós colonial. E para além de um e de outro. In: Travessias. Números 6/7. Orgs: Elísio Estanque, Hermes Augusto Costa, Maria José Canelo, Silvia Ferreira, António Casimiro Ferreira e Rui Bebiano. Centro de Estudos Sociais, Coimbra, p. 15-36, 2008.

CANDAU, Joël. Memória e Identidade; tradução Maria Letícia Ferreira. - I. ed., 4. reimpressão. São Paulo: Contexto, 2018.

FANON, Frantz. Pele negra, máscaras brancas / Frantz Fanon; tradução de Renato da Silveira. Salvador: Editora Da Universidade Federal da Bahia - EDUFBA, 2008.

Os condenados da terra. Tradução de Serafim Ferreira; Editora Ulisseia limitada: Lisboa, 1961.

KILOMBA, Grada. A máscara: colonialismo, Memória, Trauma e Descolonização. In: KILOMBA, Grada. Memórias da plantação: episódios de racismo cotidiano. Tradução de Jessica Oliveira de Jesus. Rio de Janeiro: Editora Cobogó, 2019.

LE GOFF, Jacques. História e Memória / Jacques Le Goff; tradução Bernardo Leitão. [et al.] Campinas, SP Editora da UNICAMP, 1990. (Coleção Repertórios).

MBEMBE, Achille. Crítica da razão negra. Trad. Maria Lança. ${ }^{\circ}$ ed. Lisboa, Portugal: Antígona, 2014 . 